\title{
Effect of Improved Primary Care Access on Quality of Depression Care
}

\author{
Leif I. Solberg, $M D$ \\ A. Lauren Crain, $\mathrm{PbD}$ \\ JoAnn M. Sperl-Hillen, MD \\ Mary C. Hroscikoski, MD \\ Karen I. Engebretson, BA \\ Patrick J. O'Connor, MD, MPH \\ HealthPartners Research Foundation, \\ Minneapolis, Minn
}

\begin{abstract}
PURPOSE We wanted to determine whether a major improvement in access to primary care during 2000 was associated with changes in the quality of care for patients with depression.

METHODS Health plan administrative data were analyzed by multilevel regression to compare the quality of care received by patients with depression between 1999 and 2001, a time without major changes in depression care guidelines. Approximately 6,000 patients with depression who received all care in a large multispecialty medical group during any single year were subjects for this study. Thirteen different quality measures assessed process quality under the dimensions of effectiveness, timeliness, safety, and patient-centeredness.

RESULTS The largest change was a reduction in the proportion of depressed patients with no follow-up visit in primary care after starting a new antidepressant medication: from $33.0 \%$ before a change in access to care to $15.4 \%$ afterward, $P=.001$. During the same period, continuity of care in primary care improved ( $>50 \%$ of primary care visits to 1 doctor increased from $67.3 \%$ to $74.0 \%, P=$ $<.001$ ), as did persistence of 6 -month antidepressant medication (from $46.2 \%$ to $50.8 \%, P=<.001)$. Further analyses found that the latter change was primarily associated with the change in continuity of care. Measures of subspecialty mental health care worsened during this time.
\end{abstract}

CONCLUSION Marked improvement in access to primary care for 1 year was associated with some improvement in primary care for patients with depression, but the mechanism appeared to be improved continuity. Those planning to implement advanced access to care need to do so in such a way that continuity of care is enhanced rather than harmed by the change.

Ann Fam Med 2006;4:69-74. DOI: 10.1370/afm.426.

\section{INTRODUCTION}

0 erious deficits in the quality of medical care in the United States were highlighted by the Institute of Medicine (IOM) 2001 report Crossing the Quality Chasm. ${ }^{1}$ This report identified 6 domains or aims of quality: safety, timeliness, effectiveness, efficiency, equity, and patient-centeredness, each of which had large gaps between "the care we have and the care we could have." Although the report identified a whole series of recommendations to improve quality, it did not address the relationship between the different domains, and it is unclear whether improvements in any particular domain will improve others as well.

Although the IOM reports dramatically raised the national awareness about quality, it is not clear that much has happened to change care since then, with the possible exception of what the IOM called "timeliness" ("reducing waits and sometimes harmful delays"). Recent articles suggest that many medical groups are making substantial improvements in access to primary care through using an advanced access model of patient scheduling or Second Generation Open Access., ${ }^{2,3}$ In this approach, the goal is to offer patients an office visit with the patient's personal physician the same day the
Leif I. Solberg, MD

HealthPartners Research Foundation

PO Box 1524, MS\#21111R

Minneapolis MN 55440-1524

leif.i.solberg@healthpartners.com 
patient requests one (if that physician is in the office that day and if the patient wants an appointment that day).

Although most reports about successful implementation of advanced access are either anecdotal or case studies, there is some reason to believe improved access to one's personal physician would result in improved quality of patient care. Not only has continuity of care been linked to improved quality of care for a variety of conditions ${ }^{4-8}$ it has been found to improve the likelihood of receiving preventive services, to decrease hospitalizations and visits to emergency departments and urgent care, and to improve the quality of diabetes care. It would be important to be able to show that improving access and continuity in primary care simultaneously improved care for patients with other chronic conditions, such as depression, because quality of care for these conditions was highlighted by the IOM report as a special need. ${ }^{1}$ In fact, a follow-up committee of the IOM reported that of the top 20 high-priority conditions needing improvement, 17 were chronic conditions, including depression. ${ }^{9}$

Our large multispecialty medical group had recently improved patient access to primary care clinicians. During the course of 1 year (2000), the time patients had to wait for an appointment in 17 primary care clinics improved from an average of 17.8 days in 1999 to 4.2 days in 2001 (a 76\% improvement). By 2001, the range of third next available appointments among 17 primary care clinics in 2001 varied from 6.2 to 1.7 days.

We have previously shown that improvement in access to care was associated with an improvement in personal physician continuity for patients with depression, diabetes, or coronary heart disease. ${ }^{10}$ We therefore hypothesized that during the period of 1999 to 2001, improvement in access to care would also be associated with improvement in quality of care for depression and these other conditions. Some have voiced concern, however, that quality of care for patients with chronic conditions might not benefit from improvements in access, because these patients need regular periodic monitoring and follow-up. ${ }^{11,12}$ The principal architect of advanced access has even suggested that such patients may fare better with prescheduled visits rather than expecting them to make the appointment on the day their routine follow-up is needed. ${ }^{2}$

Using depression as an example of a chronic condition, we conducted this study to assess the impact of increased access on the quality of care for patients with depression.

\section{METHODS}

This study was conducted in a 550-physician multispecialty medical group that is owned by a health plan with 650,000 members. About 240,000 of these members are cared for by the medical group, most in the
17 primary care clinics included in this study. In late 1999, the medical group's leadership decided to undertake a major change in approach to access, hoping to improve patient satisfaction as well as overall efficiency. After selecting the advanced access model of patient scheduling, the leadership engaged outside consultants to help conduct a series of 1 - to 2 -day sessions during 2000 for improvement teams from all its primary care clinics and provided considerable training and consultative resources. A deadline (January 1, 2001) was set for every clinic to have achieved full advanced access in which a patient would have an opportunity to have an appointment the same day with the clinician of choice (if present). The access transformation involved standardizing appointment types from hundreds in primary care to only a few across the organization, working down the backlog of appointments, and making repeated measurements of key indicators of access to track progress and direct further change efforts. Each clinic had considerable latitude in timing and approach to backlog reduction and regular feedback on its access statistics compared with other clinics. For other details about this transformation, see Solberg et al. ${ }^{13}$

For this study, adult (aged $>18$ years) patients with depression were identified from health plan administrative databases using algorithms modified from a previously described study and validated against chart audits. ${ }^{8}$ We defined and validated 2 different definitions for depression, because some quality measures (eg, the Health Plan Employer Data and Information Set [HEDIS] measures) require that a patient start taking a new antidepressant medication, whereas others apply to patients at any level or type of depression management. In either case, the International Classification of Diseases, Ninth Revision [ICD-9], codes included were 296.2x (major depression, single), 296.3x (major depression, recurrent), 300.4 (dysthymic disorder), and 311 (depressive disorder NOS). Chart audits resulted in a $90 \%$ to 95\% positive predictive value for each definition.

Definition A applied to patients on newly prescribed antidepressants. It required all the following criteria: (1) a 6-month period free of any antidepressant prescription being filled before the fill date for a new depression medication within the calendar year being studied (2) $_{1}$ ICD-9 code (inpatient or outpatient) for depression within 3 months before and 3 months after the date the new medication prescription was filled; and (3) 1 additional code or 1 additional prescription for an antidepressant filled during the year before or after the calendar year being studied

Definition B applied to a much larger group of depression patients by requiring either (1) 2 or more outpatient or (2) 1 or more inpatient ICD-9 codes for depression in a given calendar year, regardless of whether an antidepressant medication was started or used. Patients 
who met the criteria for each definition were selected for the years 1999 to 2001 provided they were enrolled in the group for at least 11 months of that year.

While developing and validating these definitions, we collected or developed a series of quality measures for depression care and categorized them under the domains suggested by the Institute of Medicine (Table 1). ${ }^{1}$ Because this study was retrospective, we were forced to rely on existing administrative data for all measures. In addition, unlike other chronic conditions, there were no outcome measures for quality of depression care from available administrative data. For example, all of the HEDIS measures for depression are process measures and fit within the "effectiveness" dimension, and all but one are limited to case definition A.

Our primary interest was whether these quality measures were affected by implementation of advanced access. Changes in access to care were measured (in days to next available appointment for each primary care physician) through existing administrative mechanisms associated with the improvement effort, which varied slightly in their methods from one year to the next. Continuity of care was computed yearly for each patient using a method that considers the distribution of visits by a patient among different clinicians and yields a number ranging from 0 to 1 , where higher numbers indicate more continuity of care with a single clinician. ${ }^{10}$

Patient characteristics calculated for each patient in each study year that were candidates for administrative data covariates in the analyses included age, sex, modified Charlson score, ${ }^{14}$ and diagnosis of diabetes mellitus or coronary heart disease. Additional patient characteristics included the mean number of outpatient and primary care visits, antidepressant medication possession ratio (proportion of days patients were taking prescribed antidepressant medications to all days after first prescription was filled), proportion of patients who had been hospitalized for mental health reasons, and proportion of patients taking an antidepressant.

Multivariate logistic regression was used to assess changes in the quality measures in 2000 and 2001 relative to 1999 (before the change in access in 2000), controlling for sex, age, and comorbidity (Charlson score $>1$ or presence of diabetes or heart disease) to eliminate the possibility of confounding. The unit of analysis was patient-year except for a few cases in which a 2-level multilevel model (year within patient) was specified. As a result, the analysis included yearly observations per person and controlled for the withinperson correlated data structure. Mediation analysis showed that access interval and continuity of care were independently associated with continuation of treatment. We evaluated the intraclass correlation coefficients (ICCs) by clinic for each quality measure and found no significant ICC. The yearly observed values for the quality measures are reported here for ease of interpretation. The observed and model-predicted values were nearly identical in all models, and the size of the differences in quality measures between years (of primary interest to the research question) is the same regardless of which values are used.

A second set of analyses was conducted to better understand the relationship between 2 quality measures (continuationphase treatment, optimal practitioner contact) and continuity of care. Each of these 2 quality measures was predicted from continuity of care, controlling 
for patient age, sex, and comorbidity to assess whether improved continuity of care was predictive of better treatment or follow-up.

All steps in the development of the identification system, aggregation of data, and data analysis were approved in advance and monitored by the local institutional review board (IRB). Because aggregate de-identified claims data were used in the analysis, the IRB did not require informed consent.

\section{RESULTS}

Table 2 shows the number of patients in the care system that fit the 2 definitions of depression for each of the 3 years of the study. Although the overall medical group population was gradually declining during this time, the number of depressed patients identified by each definition was increasing. The tendency not to regularly follow up patients with depression, as is done for other patients with chronic conditions, was evidenced by only 1,081 patients (about $17 \%$ each year) that fit definition $B$ in all 3 years.

The top portion of the table displays the characteristics of all patients with depression in each of the 3 study years, followed by the access measure and the continuity of care predictor used in the main analysis. It is also noteworthy that the prevalence of diabetes and coronary heart disease in patients meeting either definition of depression was about $50 \%$ higher than among the medical group's other adult patients.

The 13 quality measures in Table 1 are depicted for each year in Table 3, along with the tests of signifi-

\section{Table 2. Descriptive Characteristics of Patients With Depression} Using Either Case Definition (Using 1999 as Baseline)

\begin{tabular}{|c|c|c|c|}
\hline Characteristic & 1999 & 2000 & 2001 \\
\hline Either case definition, $\mathrm{N}$ & 6,609 & 6,988 & 7,284 \\
\hline Definition A - new antidepressant, n & 2,811 & 2,942 & 3,041 \\
\hline Definition B - any depression, $\mathrm{n}$ & 5,803 & 6,037 & 6,336 \\
\hline Age in $1998, y$ & 46.0 & 45.5 & $44.8^{*}$ \\
\hline Sex, \% male & 32.1 & 31.6 & 31.8 \\
\hline Charlson score $\geq 1, \%$ & 21.4 & $22.9^{+}$ & $24.3^{*}$ \\
\hline Diabetes mellitus, \% & 7.5 & 8.1 & $8.9 *$ \\
\hline Coronary heart disease, $\%$ & 4.9 & 5.5 & $6.0^{*}$ \\
\hline No. of clinic visits, mean & 10.8 & 10.9 & $10.4^{*}$ \\
\hline No. of primary care visits, mean & 3.5 & $4.2^{*}$ & $4.4^{*}$ \\
\hline Any hospitalization, \% & 19.9 & 20.7 & $21.7^{\dagger}$ \\
\hline Taking an antidepressant, \% & 86.4 & 86.3 & 85.5 \\
\hline Medication possession ratio ${ }^{\ddagger}$ & 0.84 & 0.84 & 0.84 \\
\hline Third next available, $d$ & 19.4 & $7.4^{*}$ & $4.5^{*}$ \\
\hline Continuity of care & 0.60 & 0.61 & $0.63^{*}$ \\
\hline \multicolumn{4}{|c|}{$\begin{array}{l}\text { * } P<.01 \text { relative to } 1999 . \\
\dagger P<.05 \text { relative to } 1999 . \\
\text { ₹ Days patient was taking medication/the total potential days (from claims data), where } 1.0=\text { perfect } \\
\text { correspondence. }\end{array}$} \\
\hline
\end{tabular}

cance, comparing findings from years 2000 and 2001 with those from 1999 and controlling for age, sex, and comorbidity (ie, Charlson score $>0$, diagnosis of diabetes mellitus, or diagnosis of coronary heart disease). Depressed patients with a comorbid condition were slightly, but not significantly, less likely to have appropriate treatment and follow-up in the analyses, predicting changes in these measures in 2000 and 2001 relative to 1999 and controlling for age, sex $(P<.09, P<.06$, respectively). The greatest change during this time was a decrease in the proportion of depressed patients who have had no follow-up visits after starting a new antidepressant. There was also an increase in overall continuity of primary care for depressed patients, but not in continuity of depression care (as evidenced by depression visit codes). During the same time, acuteand continuation-phase treatment improved, while the proportion of patients who had "optimal clinician contact" declined slightly, and the proportion with 3 or more primary care visits did not change at all.

The other striking change during this time was a parallel decrease in the proportion of primary care depression patients who had a visit with a mental health therapist and who had a mental health visit within 30 days of a hospitalization for a mental illness. Less striking was a temporary increase in the proportion of depressed patients who departed from the medical group in 2000, going from $1.0 \%$ in 1999 to $1.5 \%$ in 2000 ( $P=$ .02 ) and back down to $1.2 \%$ in 2001 (data not shown).

Additional analyses in which yearly primary care continuity by physician predicted these continuationphase treatment and optimal clinician contact changes clarified some of the findings in Table 3 . Continuity of care increased during the study years and was associated with a significant improvement in continuation treatment $(0.8 \%$ for each 0.25 increase in continuity of care from 0.0 to $1.0, P=$ $.037)$ but was not associated with a change in optimal visits $(P=.31)$

\section{DISCUSSION}

These results suggest that marked improvement in access to primary care in this medical group appears to have been associated with some changes in the care process for patients with depression. Those changes were mixed, however, with more patients having at least some followup and better continuity of care, but no more having the regular repeated followup of the sort that according to findings of recent randomized controlled trials 


\begin{tabular}{|c|c|c|c|c|c|}
\hline Measure & $\begin{array}{l}1999 \\
\%\end{array}$ & $\begin{array}{c}2000 \\
\%\end{array}$ & $\begin{array}{c}P \\
\text { Value }\end{array}$ & $\begin{array}{c}2001 \\
\%\end{array}$ & $\begin{array}{c}P \\
\text { Value }\end{array}$ \\
\hline \multicolumn{6}{|l|}{ Effectiveness } \\
\hline Acute treatment & 64.1 & 66.2 & .09 & 67.7 & .003 \\
\hline Continuation treatment & 46.2 & 48.6 & .04 & 50.8 & .000 \\
\hline Optimal clinician contact & 22.8 & 20.5 & .02 & 19.7 & .001 \\
\hline $\begin{array}{l}\text { Follow-up after mental health } \\
\text { hospitalization }\end{array}$ & 65.9 & 58.2 & .09 & 50.3 & .001 \\
\hline Optimal primary care contacts & 1.6 & 2.0 & .41 & 2.0 & .34 \\
\hline No primary care follow-up & 33.0 & 20.3 & .001 & 15.4 & .001 \\
\hline Mental health collaboration & 37.6 & 34.2 & .04 & 30.7 & .001 \\
\hline \multicolumn{6}{|l|}{ Safety } \\
\hline Emergency department visits & 25.6 & 25.8 & .77 & 27.3 & .13 \\
\hline $\begin{array}{l}\text { Emergency department visit or } \\
\text { hospitalization for mental health }\end{array}$ & 6.5 & 6.2 & .34 & 6.3 & .34 \\
\hline \multicolumn{6}{|l|}{ Timeliness } \\
\hline Prompt follow-up on new medication & 42.2 & 40.6 & .16 & 40.1 & .04 \\
\hline Prompt medication switch follow-up & 40.2 & 40.2 & .86 & 39.3 & .19 \\
\hline \multicolumn{6}{|l|}{ Patient-centeredness } \\
\hline Continuity of primary care visits & 67.3 & 72.7 & .000 & 74.0 & $<.001$ \\
\hline $\begin{array}{l}\text { Continuity of mental health primary } \\
\text { care visits }\end{array}$ & 87.1 & 87.7 & .43 & 88.0 & .22 \\
\hline
\end{tabular}

\section{Figure 1. Depression Care Quality Changes Over Time}

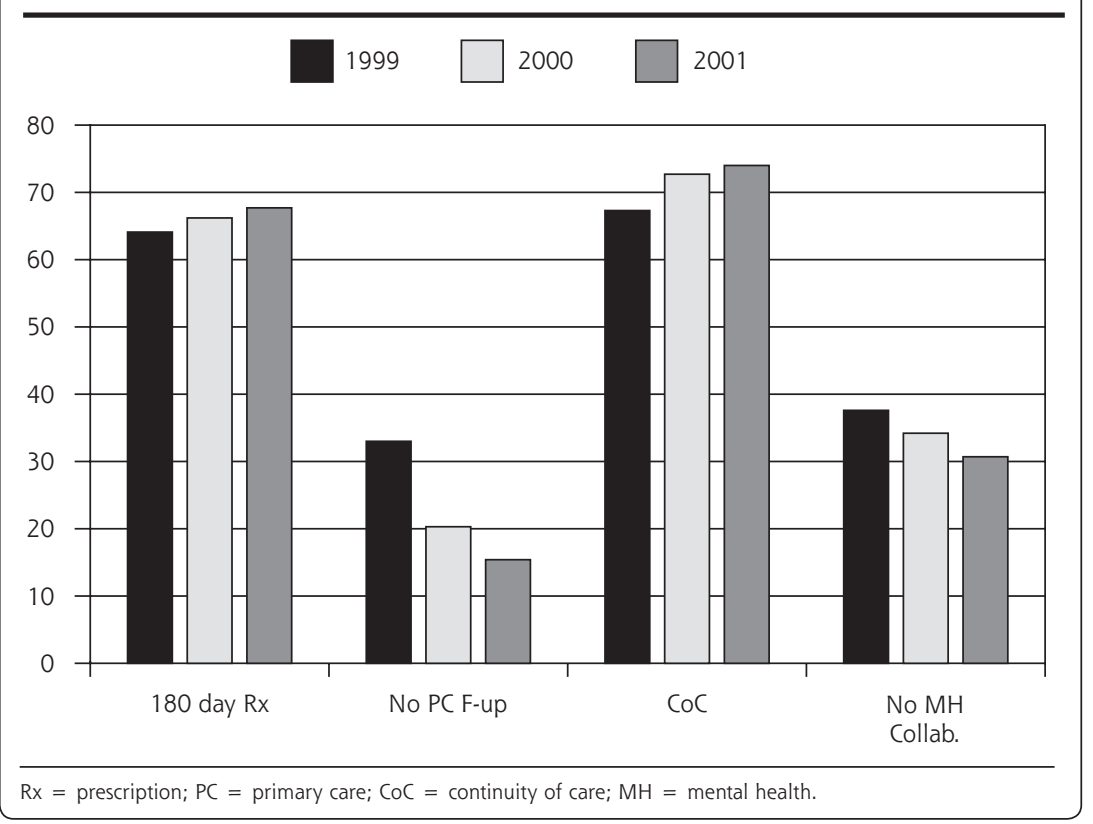

with mental health therapists, both through referrals from primary care and from follow-up after mental health hospitalizations. We suspect that the latter problems might be related to the widening differences in access to primary care and mental health clinicians (the latter specialty service continued to have access delays of several months), and there was no concurrent effort to change the approach to managing patients with depression during this period among either primary care or mental health caregivers.

The finding that continuity of care is what really matters for medication continuation reinforces previous studies of the value of continuity for chronic conditions such as diabetes. ${ }^{8,21,22}$ Several other studies have found improvement in preventive services and utilization with increased continuity of care, but only Belardi et al have found an association between access improvements and continuity of care (and that was in a residency clinic). ${ }^{23-25}$ Results show the importance of including a separate focus on continuity of care when working to improve access, which is what this medical group did in its access transformation. Some groups, however, appear to have created access changes in such a way that continuity would be likely to deteriorate by not allowing patients to preschedule follow-up visits. In the study of an advanced access initiative in the United Kingdom by Pickin et al, ${ }^{12}$ one of the main fears reported by practitioners was that access improvement efforts would worsen continuity of care.

It remains troublesome that so few patients received what would appear to be optimal follow-up. Solberg et $\mathrm{a}^{26}$ found that in this same medical group, primary care patients with depression frequently lack follow-up and follow-through. If these features are to improve, it is clear that something more than access must change. As noted by both Solberg et $\mathrm{a}^{27}$ and Pincus et $\mathrm{al}_{1}{ }^{28}$ major 
improvement in depression care will require a combination of clinical and systems changes.

Several factors limit the interpretation of our data. Most importantly, our study design precludes causal inference. It is certainly possible that concurrent events or a temporal trend affected these measures, although we identified no other changes that might affect the care of patients with depression during this time, other than reductions in nurse and physician staffing in primary care in 2001. Second, measures were based on administrative data not collected for research purposes, although there is no reason to believe that any coding or other problems with this data source changed during this period. The retrospective design made it impossible to measure systematically care outcomes for depression. Finally, we were unable to quantify telephone contacts, because there were no associated claims, so it is possible (though unlikely) that our measure of contacts is lower than what actually occurred.

Nevertheless, this quantitative study is the first to analyze apparent effects of change in visit access on the quality of care for patients with a chronic condition. We found mixed effects of increased primary care access on depression care, with improvement in antidepressant medication use being associated with improved continuity of care. These mixed results suggest that more substantive improvements in quality of depression care require more focus on specific aspects of that care, including more systematic follow-up of patients and greater attention to integration of primary care and mental health subspecialty care.

To read or post commentaries in response to this article, see it online at http://www.annfammed.org/cgi/content/full/4/1/69.

Key words: Continuity of patient care; depression; primary health care/ organization $\&$ administration; quality of health care; health services accessibility

Submitted June 14, 2005; submitted, revised, July 21, 2005; accepted August 15, 2005.

Funding support: Supported by grant \#041868 from The Robert Wood Johnson Foundation through the Improving Chronic Illness Care Initiative.

\section{REFERENCES}

1. Institute of Medicine. Crossing the Quality Chasm: A New Health System for the 21st Century. Washington, DC: National Academy Press; 2001.

2. Murray M, Berwick DM. Advanced access: reducing waiting and delays in primary care. JAMA. 2003;289:1035-1040

3. Murray M, Bodenheimer T, Rittenhouse D, Grumbach K. Improving timely access to primary care: case studies of the advanced access model. JAMA. 2003;289:1042-1046.

4. Bindman AB, Grumbach K, Osmond D, Vranizan K, Stewart AL. Primary care and receipt of preventive services. J Gen Intern Med. 1996; 11:269-276.

5. Gill JM, Mainous AG, 3rd, Nsereko M. The effect of continuity of care on emergency department use. Arch Fam Med. 2000;9:333-338.
6. Mainous AG, 3rd, Gill JM. The importance of continuity of care in the likelihood of future hospitalization: is site of care equivalent to a primary clinician? Am J Public Health. 1998;88:1539-1541.

7. Plauth $A E$, Pearson SD. Discontinuity of care: urgent care utilization within a health maintenance organization. Am J Manag Care. $1998 ; 4: 1531-1537$

8. O'Connor PJ, Desai J, Rush WA, et al. Is having a regular provider of diabetes care related to intensity of care and glycemic control? J Fam Pract. 1998;47:290-297.

9. Institute of Medicine. Committee on Identifying Priority Areas for Quality Improvement. Quality Areas for National Action: Transforming Health Care Quality. Washington, DC: National Academies Press; 2003.

10. Solberg LI, Maciosek MV, Sperl-Hillen JM, et al. Does improved access to care affect utilization and costs for patients with chronic conditions? Am J Manag Care. 2004; 10:717-722.

11. Salisbury C. Does advanced access work for patients and practices? $\mathrm{Br}$ J Gen Pract. 2004;54:330-331.

12. Pickin M, O'Cathain A, Sampson FC, Dixon S. Evaluation of advanced access in the national primary care collaborative. Br J Gen Pract. 2004;54:334-340.

13. Solberg LI, Hroscikoski MC, Sperl-Hillen JM, O'Connor PJ, Crabtree BF. Key issues in transforming health care organizations for quality: the case of advanced access. Jt Comm J Qual Saf. 2004;30:15-24.

14. Rius C, Perez G, Martinez JM, et al. An adaptation of Charlson comorbidity index predicted subsequent mortality in a health survey. J Clin Epidemiol. 2004;57:403-408.

15. Hunkeler EM, Meresman JF, Hargreaves WA, et al. Efficacy of nurse telehealth care and peer support in augmenting treatment of depression in primary care. Arch Fam Med. 2000;9:700-708.

16. Simon GE, VonKorff M, Rutter C, Wagner E. Randomised trial of monitoring, feedback, and management of care by telephone to improve treatment of depression in primary care. BMJ. 2000;320:550-554.

17. Wells KB, Sherbourne C, Schoenbaum M, et al. Impact of disseminating quality improvement programs for depression in managed primary care: a randomized controlled trial. JAMA. 2000;283:212-220.

18. Rost K, Nutting P, Smith J, Werner J, Duan N. Improving depression outcomes in community primary care practice: a randomized trial of the quEST intervention. Quality Enhancement by Strategic Teaming. J Gen Intern Med. 2001;16:143-149.

19. Rost K, Nutting P, Smith JL, Elliott CE, Dickinson M. Managing depression as a chronic disease: a randomised trial of ongoing treatment in primary care. BMJ. 2002;325:934.

20. Rubenstein LV, Jackson-Triche M, Unutzer J, et al. Evidence-based care for depression in managed primary care practices. Health Aff (Millwood). 1999;18:89-105.

21. Hanninen J, Takala J, Keinanen-Kiukaanniemi S. Good continuity of care may improve quality of life in Type 2 diabetes. Diabetes Res Clin Pract. 2001;51:21-27.

22. Overland J, Yue DK, Mira M. Continuity of care in diabetes: to whom does it matter? Diabetes Res Clin Pract. 2001;52:55-61.

23. Belardi FG, Weir S, Craig FW. A controlled trial of an advanced access appointment system in a residency family medicine center. Fam Med. 2004;36:341-345.

24. Saultz JW, Lochner J. Interpersonal continuity of care and care outcomes: a critical review. Ann Fam Med. 2005;3:159-166.

25. Flach SD, McCoy KD, Vaughn TE, et al. Does patient-centered care improve provision of preventive services? J Gen Intern Med. 2004;19:1019-1026

26. Solberg LI, Fischer LR, Rush WA, Wei F. When depression is the diag nosis, what happens to patients and are they satisfied? Am J Manag Care. 2003;9:131-140.

27. Solberg LI, Korsen N, Oxman TE, Fischer LR, Bartels S. The need for a system in the care of depression. J Fam Pract. 1999;48:973-979.

28. Pincus HA, Pechura CM, Elinson L, Pettit AR. Depression in primary care: linking clinical and systems strategies. Gen Hosp Psychiatry. 2001;23:311-318. 